\title{
Comment on GSK3ß Polymorphisms and Colorectal Cancer
}

\author{
Sora Yasri, $\mathrm{MD}^{1 *}$; Viroj Wiwanitkit, $\mathrm{MD}^{2}$ \\ ${ }^{1}$ Private Academic Consultant, Bangkok, Thailand \\ ${ }^{2}$ Dr. DY Patil University, Pune, India
}

\section{Dear Editor,}

We read the publication on "GSK3 $\beta$ Polymorphisms Are Associated with Tumor Site and TNM Stage in Colorectal Cancer (CRC)" with great interest. ${ }^{1}$ Rosales-Reynoso et al. concluded that "GSK3 $\beta$ gene polymorphisms play a significant role in promoting or preventing CRC". ${ }^{1}$ This report is a report that can add to the data on the relationship between GSK3 $\beta$ Polymorphisms and CRC. Considering $\mathrm{T}>\mathrm{C}$ GSK3 $\beta$ Polymorphism as a single genetic factor, the possible molecular mechanism that might be related to the clinical association with CRC is due to the genetic variant induce molecular weight change. Based on the molecular calculation according to standard technique presented in the previous referencing studies, ${ }^{2}$ the molecular weight change due to $\mathrm{T}>\mathrm{C}$ GSK3 $\beta$ Polymorphism is equal to $-15 \mathrm{~g} / \mathrm{mol}$ (from 126.1 to $111.1 \mathrm{~g} / \mathrm{mol})$. Nevertheless, not only GSK3 $\beta$ Polymorphisms but also other genetic polymorphisms can have clinical impacts on CRC. ${ }^{3}$ Some good examples of those genetic polymorphisms are MMP-7 Gene Promoter
Region and UCP2 polymorphisms. ${ }^{4,5}$ In the present report, Rosales-Reynoso et al. studied only GSK3 $\beta$ Polymorphisms and cannot rule out the possible effects of other polymorphisms.

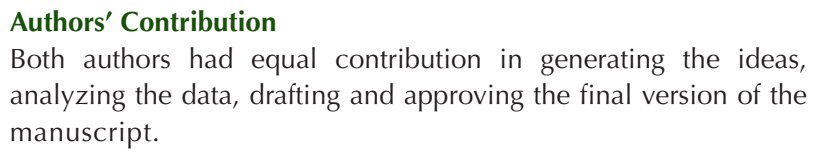
analyzing the data, drafting and approving the final version of the manuscript.

\section{Conflict of Interest Disclosures}

None.

Ethical Statement

Not applicable.

\section{References}

1. Rosales-Reynoso MA, Zepeda-López P, Saucedo-Sariñana AM, Pineda-Razo TD, Barros-Núñez $P$, Gallegos-Arreola MP, et al. GSK3区 Polymorphisms Are Associated with Tumor Site and TNM Stage in Colorectal Cancer. Arch Iran Med. 2019;22(8):453-60.

2. Joob S. Guran M. PRDM1 rs1010273 polymorphism and survival of patients with hepatitis B virus-related hepatocellular carcinoma. Adv Lab Med Int. 2019;9:31-2.

3. Mates IN, Jinga V, Csiki IE, Mates D, Dinu D, Constantin A, Jinga M. Single nucleotide polymorphisms in colorectal cancer: associations with tumor site and TNM stage. J Gastrointestin Liver Dis. 2012;21(1):45-52.

4. Jiang Y, Yang Y, Yang T, Li Y, Chen L, Yan J. Association of UCP2 rs659366 polymorphisms with the outcomes of patients after surgery for colorectal cancer. Zhejiang Da Xue Xue Bao Yi Xue Ban. 2018;47(2):143-9.

5. Dziki Ł, Przybyłowska K, Majsterek I, Trzciński R, Mik M, Sygut A. A/G polymorphism of the MMP-7 gene promoter region in colorectal cancer. Pol Przegl Chir. 2011;83(11):6226. doi: 10.2478/v10035-011-0098-1. 